\title{
Chronic tracheoesophageal fistula successfully treated using Amplatzer septal occluder
}

Tracheoesophageal fistula (TEF) is a serious life-threatening condition that appears in critically ill patients with a prolonged history of mechanical ventilation. Enteral feeding and dietary support combined with surgery is the gold standard. In selected patients, TEF healing can be ensured by a mini-invasive approach using an Amplatzer septal occluder (AGA Medical Corporation), intended for cardiac septal defect closure [1]. The Amplatzer septal occluder, which is composed of a nitinol mesh, has two self-expandable disks connected by a thin diameter waist ( $\triangleright$ Fig. 1) and ensures mechanical closure of the two sides of the fistula, making a potential platform for subsequent tissue ingrowth [2].

This technique was used in a 44-year-old man with tracheostomy and a history of protracted invasive lung support. He had been diagnosed as having a TEF after numerous episodes of aspiration pneumonitis and had subsequently undergone anterior cervicotomy with surgical closure of the fistula. After 7 months, his dysphagia relapsed. Endoscopy confirmed recurrence of the TEF ( $\triangleright$ Fig.2), which was initially treated unsuccessfully by submucosal injection of acrylic glue.

Given the poor clinical condition of the patient and the failure of both surgical and endoscopic therapy, it was decided to try positioning of an Amplatzer septal occluder ( $\triangleright$ Video 1$)$. The procedure was performed using a gastroscope (GIF-1TH190; Olympus Europe) and a bronchoscope (BF-1T180; Olympus Europe). The TEF was cannulated using a papillotome (TRUETome; Boston Scientific) and a 0.025-inch guidewire (Jagwire; Boston Scientific) was inserted into the bronchial segment. The wire was then grasped with a biopsy forceps (Endo-Jaw; Olympus Europe) passed through the bronchoscope, providing countertraction by maintaining a straightened position. The septal occluder catheter was introduced and the

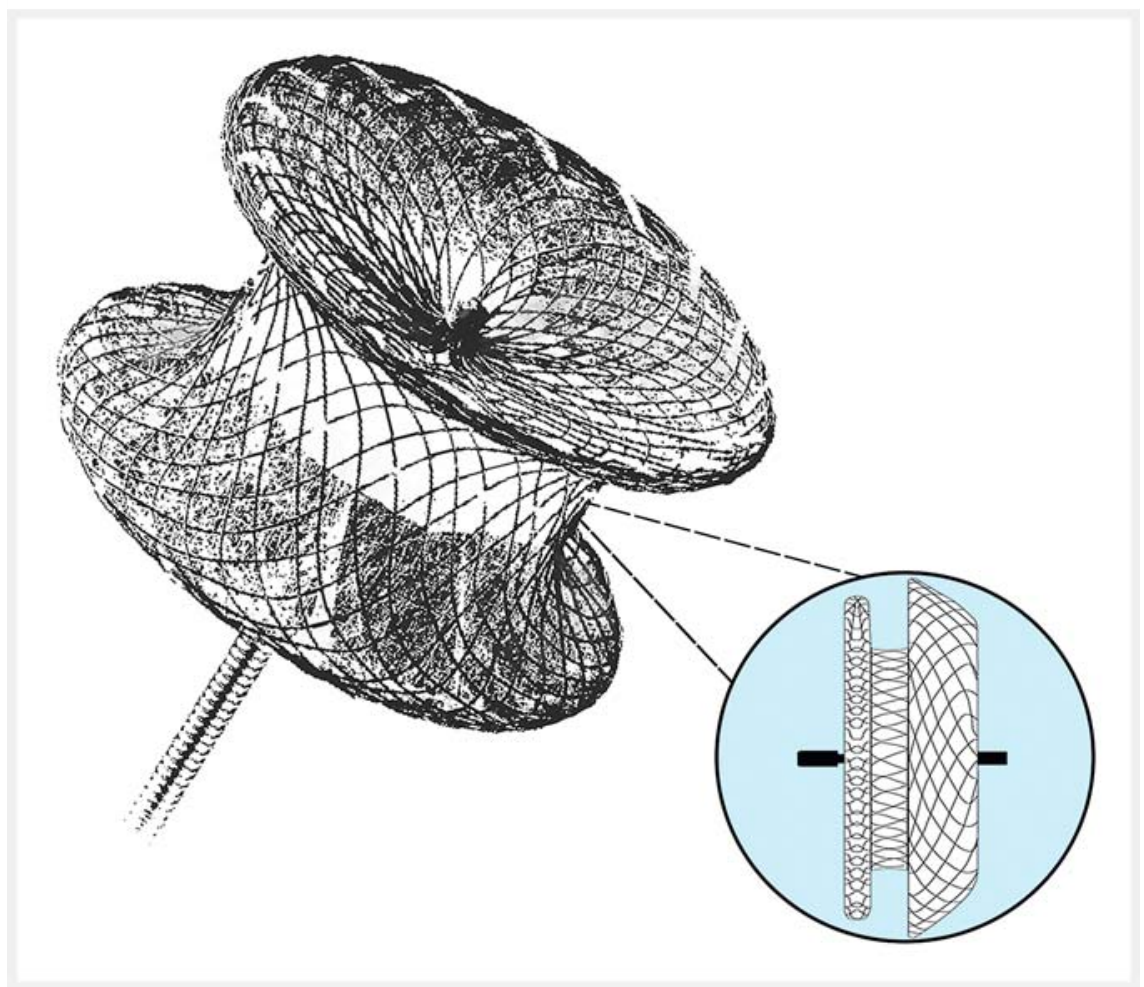

Fig. 1 Longitudinal and transverse profile of the Amplatzer septal occluder showing its typical dumbbell shape. Source: Federico Amata.
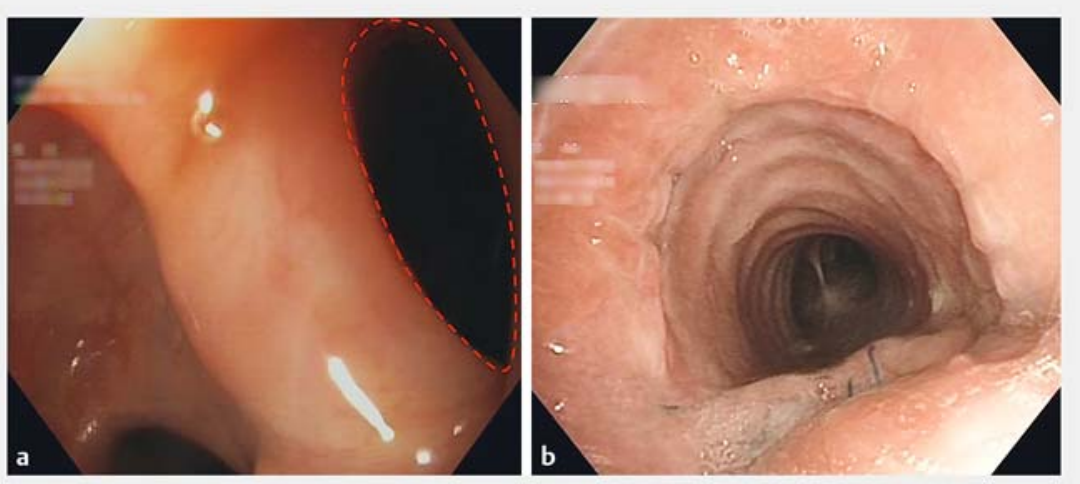

- Fig. 2 Endoscopic diagnosis of tracheoesophageal fistula recurrence was made by the finding of: $\mathbf{a}$ a fissure (red dashed line) in the anterior wall of the esophagus; $\mathbf{b}$ in communication with the tracheal lumen.

two ends were released into the trachea and esophagus, respectively ( $>$ Fig.3). Successful closure of the TEF was con- firmed by contrast medium injection ( $\triangleright$ Fig.4). The procedure was uneventful. 


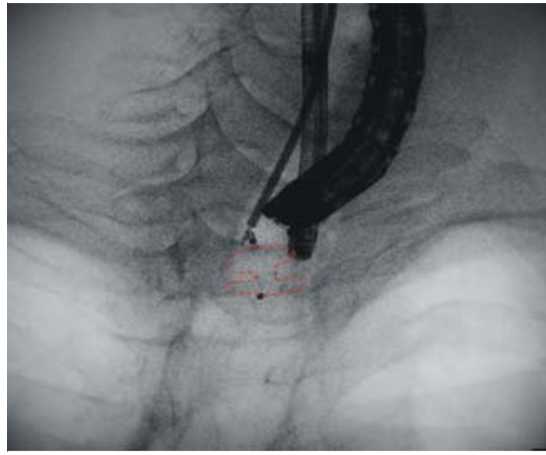

- Fig. 3 Radiographic image showing the Amplatzer septal occluder following placement (red dashed line).

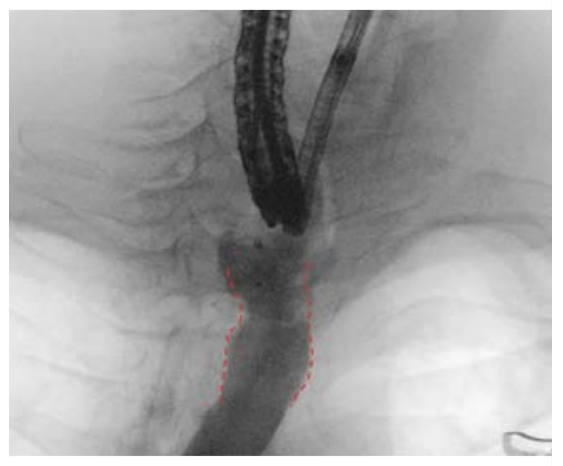

- Fig.4 Radiographic image following injection of contrast medium showing successful closure of the tracheoesophageal fistula with no contrast leakage or stenosis of the esophageal lumen (red dashed lines).

Repeat endoscopy 4 weeks later showed that the stent remained in the correct position and the patient has remained asymptomatic during 12 months of follow-up.

In selected tertiary care centers, where advanced endoscopic and catheter lab suites are available, placement of an Amplatzer septal occluder is feasible and safe $[3,4]$, offering potential fistula closure, especially in patients in a critical condition, with severe comorbidities and recurrence of a TEF.

Endoscopy_UCTN_Code_TTT_1AO_2AI

\section{Acknowledgments}

The authors gratefully acknowledge the contribution of Federico Amata for his graphic support.

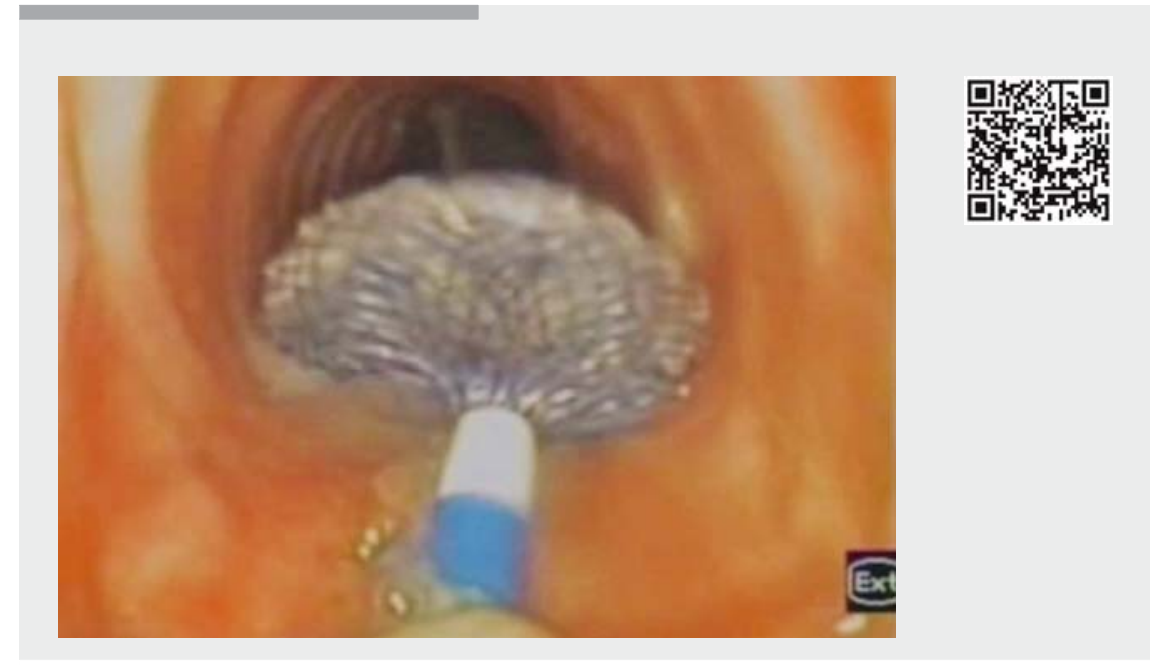

Video 1 An Amplatzer septal occluder is placed for the treatment of a chronic tracheoesophageal fistula, a mini-invasive approach in a critically ill patient.

\section{Competing interests}

None

\section{The authors}

Mario Traina', Michele Amata ${ }^{1}$, Lavinia De Monte $^{2}$, Antonino Granata ${ }^{1}$, Dario Ligresti ${ }^{1}$, Ilaria Tarantino', Caterina Gandolfo ${ }^{3}$

1 Endoscopy Service, Department of Diagnostic and Therapeutic Services, IRCCS - ISMETT, Palermo

2 Thoracic Surgery, Department of Diagnostic and Therapeutic Services, IRCCS - ISMETT, Palermo

3 Cardiac Cath Lab, Department of Diagnostic and Therapeutic Services, IRCCS - ISMETT, Palermo

\section{Corresponding author}

\section{Michele Amata, MD}

Endoscopy Service, IRCCS-ISMETT,

Via Tricomi, 5, 90127 Palermo, Italy Fax: +39-091-2192400 (specify Endoscopy Service)

mamata@ismett.edu

\section{References}

[1] Repici A, Presbitero P, Carlino A et al. First human case of esophagus-tracheal fistula closure by using a cardiac septal occluder (with video). Gastrointest Endosc 2010; 71: 867-869
[2] Scordamaglio PR, Tedde ML, Minamoto H et al. Endoscopic treatment of tracheobronchial tree fistulas using atrial septal defect occluders: preliminary results. J Bras Pneumol 2009; 35: $1156-1160$

[3] Coppola F, Boccuzzi G, Rossi G et al. Cardiac septal umbrella for closure of a tracheoesophageal fistula. Endoscopy 2010; 42: E318-E319

[4] ASGE Technology Committee, Banerjee S, Barth BA et al. Endoscopic closure devices. Gastrointest Endosc 2012; 76: 244 - 251. Erratum in: Gastrointest Endosc 2013; 77: 833

\section{Bibliography}

DOI https://doi.org/10.1055/a-0677-1531

Published online: 10.9.2018

Endoscopy 2018; 50: 1236-1237

(c) Georg Thieme Verlag KG

Stuttgart · New York

ISSN 0013-726X

\section{ENDOSCOPY E-VIDEOS}

https://eref.thieme.de/e-videos

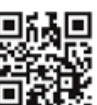

Endoscopy E-Videos is a free access online section, reporting on interesting cases and new techniques in gastroenterological endoscopy. All papers include a high quality video and all contributions are freely accessible online.

This section has its own submission website at

https://mc.manuscriptcentral.com/e-videos 